\title{
Effect of Fusicoccin on the Early Infection Process of Legume Roots by Rhizobium spp.
}

\author{
Juan Pedro Donaire, ${ }^{1}$ María Pilar Rodríguez-Rosales, ${ }^{1}$ María José Soto, ${ }^{2}$ Juan Sanjuan, ${ }^{2}$ \\ and José Olivares ${ }^{2}$ \\ ${ }^{1}$ Departamento de Bioquímica y Biología Molecular de Plantas, and ${ }^{2}$ Departamento de Microbiología del \\ Suelo y Sistemas Simbióticos, Estación Experimental del Zaidín, CSIC, Profesor Albareda, 1, E-18008 \\ Granada, Spain \\ Accepted 2 September 1999.
}

\begin{abstract}
Nod factors, the first detectable signals produced by $R h i$ zobium spp., were reported to induce cytosolic $\mathbf{p H}$ changes and plasma membrane depolarization in root hairs as specific responses. In this study, it has been found that fusicoccin inhibits nodulation of alfalfa roots. This inhibition was only observed when fusicoccin was applied in the earlier steps of the bacteria-plant interaction. The observed effect is similar to that caused by the undissociated permeant acetic acid, which decreases the cytoplasmic pH and, like fusicoccin, significantly stimulates net $\mathrm{H}^{+}$efflux. These results suggest that the fusicoccin-induced plasma membrane $\mathrm{H}^{+}$-ATPase activity and membrane hyperpolarization could be responsible for the nodulation inhibition observed. Moreover, it was found that nodulation was inhibited by removing external calcium with EGTA. When fusicoccin is present, a lower concentration of EGTA is necessary to inhibit nodulation. Furthermore, the addition of $\mathrm{Ca}^{2+}$ ionophore $\mathrm{A} 23187$ was found to inhibit $\mathrm{H}^{+}$efflux by roots. These observations support the idea that the Nod factor-triggered calcium signal modulates the activity of the proton pump.
\end{abstract}

Members of the genera Rhizobium, Bradyrhizobium, Azorhizobium, and Sinorhizobium (hereafter, rhizobia) are bacteria that establish a mutualistic symbiosis with legume roots. They form nodules where dinitrogen is reduced to ammonia that is then transferred to the host. A signal exchange between the host and the microsymbiont is necessary for the establishment of the association. Apparently, almost all plants exhibit the ability to distinguish between pathogenic and mutualistic interactions (Quigley et al. 1996). There may be similarities between pathogenic and mutualistic modes of infection and at least some elements of the molecular recognition mechanisms may be common in both cases.

In higher plants, ion transport is largely organized around hydrogen ions, and the most solidly postulated function of the plasma membrane proton pump is to maintain a large, stable, electrochemical potential difference for protons, which serves

Corresponding author: J. Olivares, Departamento de Microbiología del Suelo y Sistemas Simbióticos, Estación Experimental del Zaidín, Profesor Albareda, 1, 18008 Granada, Spain; Telephone: +34 958121 011; Fax: +34 958129 600; E-mail: olivares@eez.csic.es as the driving force for the concentration of metabolic substrates and the stabilization of intracellular $\mathrm{pH}$ (Serrano 1989). Changes in the host plasma membrane $\mathrm{H}^{+}$-ATPase activity (with the associated changes in the intracellular $\mathrm{pH}$ and membrane potential) are among the earliest events related to plant pathogen interactions (Vera-Estrella et al. 1994). It has been proposed that the differential effect of elicitors on the plasma membrane $\mathrm{H}^{+}$-ATPase and the resulting acidification or alkalinization of the extracellular medium are produced in response to the difference between specific and nonspecific elicitors (De Witt 1995).

Nod factors are the first recognizable signal produced by rhizobia when nod genes are induced by specific flavonoids exuded by the roots of the corresponding legume. However, little is known about how these signals are specifically perceived by host plant cells. It has been demonstrated that a plasma membrane depolarization (Ehrhardt et al. 1992; Kurkdjian 1995; Felle et al. 1995) and intracellular alkalinization (Felle et al. 1996) of alfalfa root hairs take place in response to Nod factors produced by Sinorhizobium meliloti. Recently, evidence has been provided for the potential role of plasma membrane $\mathrm{H}^{+}$-ATPase in the process of Nod factor-induced membrane depolarization and extracellular alkalinization (Felle et al. 1998). It was concluded that the depolarization was caused by temporary short-circuiting of the proton pump through the rapid release of $\mathrm{Cl}^{-}$ions over their steep electrochemical gradient. Moreover, the observation that the $\mathrm{Ca}^{2+}$ ionophore A23187 mimics the Nod factor response, and that the $\mathrm{Ca}^{2+}$ channel antagonist nifedipine inhibits this response, indicates a Nod signal-induced influx of calcium ions that is required for triggering the subsequent events of plasma membrane depolarization and $\mathrm{pH}$ changes. Previous work with a non-nodulating alfalfa mutant showed a periodic calcium spiking in root hairs in response to specific $S$. meliloti Nod factors (Ehrhardt et al. 1996).

In higher plants, fungal toxin fusicoccin and undissociated permeant weak acids stimulate net $\mathrm{H}^{+}$efflux and hyperpolarize the membrane potential. It has also been suggested that fusicoccin and weak acids stimulate both ATP hydrolysis and ATP-dependent $\mathrm{H}^{+}$pumping activities of plasma membrane $\mathrm{H}^{+}$-ATPase as a result of the cytoplasmic acidification that is followed by the acidification of the medium (Marre 1979; Brummer et al. 1984; Bertl and Felle 1985; Johansson et al. 1993; De Michelis et al. 1996). Likewise, it has now been 
demonstrated that fusicoccin binds to a single receptor in plants, and it has become clear that a functional FC-binding site is formed from a complex between the C-terminal regulatory domain of the $\mathrm{H}^{+}$-ATPase and 14-3-3 proteins (Baunsgaard et al. 1998). Because fusicoccin and weak acids activate the electrogenic proton pump, the aim of this work has been to determine whether the cytoplasmic acidification induced by these two factors can affect the nodulation of alfalfa roots by rhizobia, and whether the activity of the proton pump can also be related to the extracellular concentration of calcium.

\section{RESULTS AND DISCUSSION}

Results have shown that simultaneous addition of fusicoccin and bacteria causes a delay in root nodule emergence that is also detected when fusicoccin is applied $8 \mathrm{~h}$ after inoculation (Fig. 1A). A significant decrease in the number of nodules formed was also observed (Fig. 1B). The effect on nodulation is temporary since several days after nodule appearance the number of nodules per plant was almost the same. No significant effect was observed when fusicoccin was added $24 \mathrm{~h}$ after inoculation (data not shown). At that time, most of the bacteria have already entered the root hair cells. The effect on nodulation cannot be attributed to a bacteriostatic or bactericidal action of the fusicoccin since no effect on the bacterial growth rate has been observed at the concentration applied (data not shown). Previously, we also found that fusicoccin at a concentration of $125 \mathrm{nM}$ did not affect shoot and root plant development, while higher concentrations clearly caused a chlorosis.

The expression of a nodC-lacZ fusion was analyzed at different $\mathrm{pHs}$ in order to determine whether or not the low extracellular $\mathrm{pH}$ induced by fusicoccin affected the expression of nod genes. No differences in expression were observed (data not shown) at any of the $\mathrm{pHs}$ studied, even at $\mathrm{pH} 5.2$, at which the bacterial growth is hardly noticeable.

Table 1 shows that $\mathrm{H}^{+}$extrusion from excised alfalfa roots was significantly stimulated by fusicoccin. These results are in line with the effects of this diterpene glucoside on the acidification of the external medium observed in practically all the higher plant species (Marré et al. 1974; Roldan et al. 1992). Thus, the inhibition of nodulation by the fusicoccin may be a consequence of plasma membrane hyperpolarization.

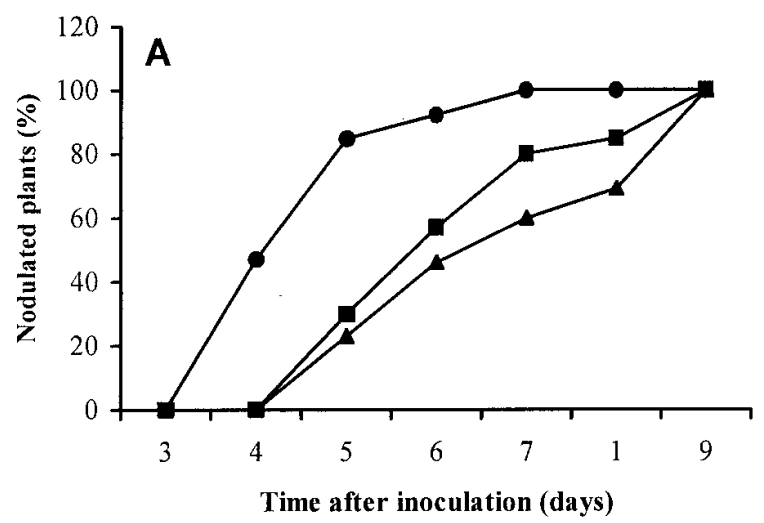

Since the hyperpolarization of plasma membrane by $\mathrm{H}^{+}$ATPase activation is important for the inhibitory effect of fusicoccin on nodulation, a control experiment was carried out with alfalfa roots in which a weak permeant acid (acetic acid) was used to change the cytosolic $\mathrm{pH}$ and the polarization of plasma membrane. A delay in the nodulation rate (Fig. 2A) and a decrease in the number of nodules formed (Fig. 2B) were found when plants were maintained for $30 \mathrm{~min}$ in a medium with a $\mathrm{pH}$ lowered to 5.0 at both concentrations of acetic acid, 4.0 and $7.5 \mathrm{mM}$. The treatment of plants at a $\mathrm{pH} 5.0$, which was obtained by adding succinic acid to the mineral solution, displayed no effect. This suggests that, rather than the external $\mathrm{pH}$, it is the intracellular acidification that is an important factor in nodulation inhibition. In this respect, the decreased intracellular $\mathrm{pH}$ that is due to the addition of acetic acid does enhance proton pumping by root cells (Table 1). This finding is consistent with the notion that cytoplasmic $\mathrm{H}^{+}$ concentration provides additional substrate for the plasma membrane $\mathrm{H}^{+}$-ATPase. This increased $\mathrm{H}^{+}$pumping, which is the result of cytoplasmic acidification, can be manifested as a membrane hyperpolarization. Moreover, the decrease of intracellular $\mathrm{pH}$ caused by acetic acid load may put limits on the increase of cytoplasmic $\mathrm{pH}$ in response to Nod factor, as was demonstrated in Medicago sativa root hairs after the addition of S. meliloti Nod factor (Felle et al. 1996).

Alternatively, the decrease in nodulation rate may be caused by a cytosolic $\mathrm{pH}$ change in response to the action of fusicoccin on the biochemical pH stat. Recently, Felle et al. (1998) have suggested that an intracellular alkalinization of the root hair cells appears to be caused by a net metabolic consumption of protons. Since, when fusicoccin is added $24 \mathrm{~h}$ after inoculation, no inhibition of nodulation was observed, it is likely that fusicoccin acts at the early stages of the interaction.

Table 1. Effects of fusicoccin, acid load, and $\mathrm{Ca}^{2+}$ ionophore A23187 on the $\mathrm{H}^{+}$extrusion of alfalfa root cells

\begin{tabular}{lc}
\hline Treatment & $\begin{array}{c}\text { Maximun rate of } \mathbf{H}^{+} \text {extrusion } \\
\left(\boldsymbol{\mu m o l ~} \mathbf{H}^{+} \cdot \mathbf{g}(\mathbf{F W})^{-\mathbf{1}} \cdot \mathbf{h}^{\mathbf{- 1}}\right)\end{array}$ \\
\hline Control & $1.18 \pm 0.05$ \\
$125 \mathrm{nM}$ fusicoccin & $1.79 \pm 0.10$ \\
$5.0 \mu \mathrm{M}$ A23187 & $0.85 \pm 0.05$ \\
Succinate & $1.20 \pm 0.08$ \\
Succinate plus acetic acid & $2.07 \pm 0.20$ \\
\hline
\end{tabular}

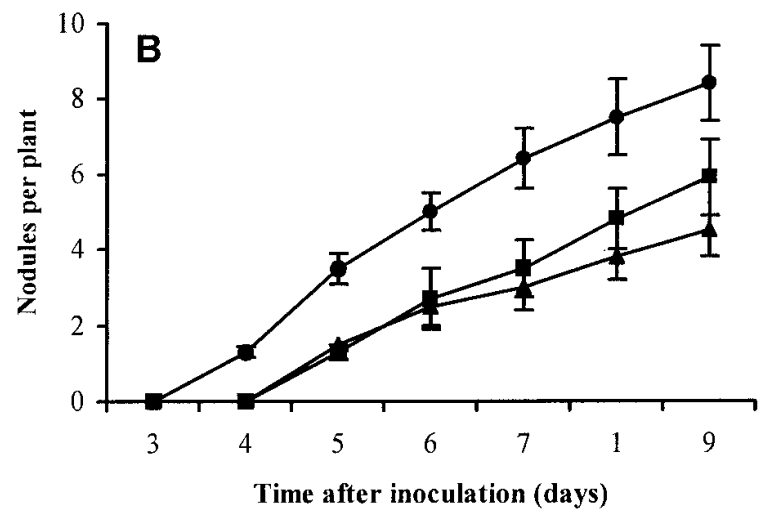

Fig. 1. Effect of $125 \mathrm{nM}$ fusicoccin on the nodulation rate of alfalfa roots. A, Percentage of nodulated plants. B, Number of nodules formed per plant. $(\boldsymbol{\Delta})$ Fusicoccin added to the mineral solution at the time of inoculation. (ם) Fusicoccin added $8 \mathrm{~h}$ later. ( $)$ Control. Experiments were conducted three times with similar results. 
Later, the signal derived from the recognition of Nod factors is transduced and the nodulation process remains unaffected by the presence of the fungal toxin. No effect of fusicoccin addition on the emergence of lateral roots was detected. The effect of fusicoccin on a gene-for-gene pathogen-resistance response (Roberts and Bowles 1999), and a possible mechanistic link between plasma membrane $\mathrm{H}^{+}$-ATPase activity and the induction of plant defense genes (Schaller and Oecking 1999) have been recently reported. According to Martínez-Abarca et al. (1998), the gene-for-gene system does not seem to operate when legumes are inoculated with their specific rhizobia. The data presented here are therefore not a consequence of a defense response.

On the other hand, since cytoplasmic calcium spiking is associated with the infection of root hairs of plants treated with specific $S$. meliloti Nod factors (Ehrhardt et al. 1996), the restriction of the passage of $\mathrm{Ca}^{2+}$ from the medium into the cell with agents that bind $\mathrm{Ca}^{2+}$, as EGTA, could either arrest or greatly inhibit nodulation. It was found that when plants were grown in a medium containing $1.0 \mathrm{mM}$ EGTA, nodulation was delayed and, moreover, only a very few nodules appeared. Furthermore, the effect of EGTA on nodulation in the presence of fusicoccin was investigated. The results (Fig. 3) indicated that, in the presence of fusicoccin $(125 \mathrm{nM})$, a lower concentration of EGTA was necessary to inhibit nodulation (Fig. 3C,D). Additional evidence in support of a relationship between the activity of the proton pump and the Nod factortriggered calcium signal was provided by the calcium ionophore A23187, which mimics the responses of the root to Nod factors with striking similarity (Felle et al. 1998). As shown in Table 1 , roots of alfalfa responded to $5 \mu \mathrm{M}$ A23187 with a clear inhibition of $\mathrm{H}^{+}$extrusion. As reported by other authors (Munns 1970; Allen et al. 1994; Eckhardt et al. 1996; Felle et al. 1998), these results also confirm that calcium plays an important role in nodulation signal response. A plausible mechanism to explain the results could be activation of plasma membrane receptors by Nod factors that could lead to $\mathrm{Ca}^{2+}$ signaling events that regulate proton pump and ion channel activity. The rapid activation of ion channels could cause membrane depolarization, allowing $\mathrm{Ca}^{2+}$ influx from the extracellular space and $\mathrm{Ca}^{2+}$ release from intracellular stores (Felle et al. 1998). The increase of cytosolic $\mathrm{Ca}^{2+}$, membrane depolarization, and other signaling events (phosporylation/de- phosphorylation of proteins) would mediate the inhibition of the proton pump and a long-term membrane depolarization by which nodulation could be regulated. Because of their role in converting ATP into electrical and $\mathrm{pH}$ gradient across the membrane, the activation of $\mathrm{H}^{+}$-ATPase and plasma membrane hyperpolarization induced by FC could interfere with the symbiotic signals implicated in nodulation.

\section{MATERIALS AND METHODS}

\section{Fusicoccin and EGTA assays.}

Ten-day-old alfalfa plants (cv. Aragón), axenically grown in test tubes as described by Olivares et al. (1980), were inoculated up to $10^{6}$ cells $\cdot \mathrm{ml}^{-1}$ of the $S$. meliloti strain GR4 (Casadesús and Olivares 1979), from a 24-h culture grown in tryptone yeast extract medium. Fusicoccin (Sigma, St. Louis, MO) at a final concentration of $125 \mathrm{nM}$ was added to the plant growth medium at the same time as bacteria, 8 or $24 \mathrm{~h}$ later. Previously, we found that fusicoccin at that concentration did not affect shoot and root plant development. Higher concentrations caused a clear chlorosis. Nodule appearance and number of nodules formed were recorded each $24 \mathrm{~h}$. $S$. meliloti GR4 containing a nodC-lacZ fusion (pRmM57) (Mulligan and Long 1985) was grown in minimal medium up to a concentration of $10^{9}$ cells $\cdot \mathrm{ml}^{-1}$. Two sets of tubes containing $3 \mathrm{ml}$ of buffered medium at $\mathrm{pH} 7.2,6.8,6.4,6.0,5.6$, and 5.2 were prepared. The tubes with the three highest $\mathrm{pH}$ were inoculated with $10^{7}$ cells $\cdot \mathrm{ml}^{-1}$, whereas those with the lowest $\mathrm{pHs}$ were inoculated with $10^{8}$ cells $\cdot \mathrm{ml}^{-1}$. Luteolin was added to one set of tubes up to $5 \mu \mathrm{M}$ and all tubes were incubated for $18 \mathrm{~h}$ at $30^{\circ} \mathrm{C}$. $\beta$-Galactosidase assays were performed as described by Miller (1972) with the same number of cells for each pH. For the assays with EGTA, this compound was added to the mineral solution at the time of inoculation with the bacteria acid at final concentrations of $0.1,0.5$, or $1.0 \mathrm{mM}$. This assay was performed in both the presence and absence of fusicoccin.

\section{Acid load treatments.}

Before the inoculation of the plants prepared as above, the mineral growth medium of one set of tubes (usually 20) was discharged under sterile conditions and pooled for its later use. The solution was substituted by a new one supplemented with
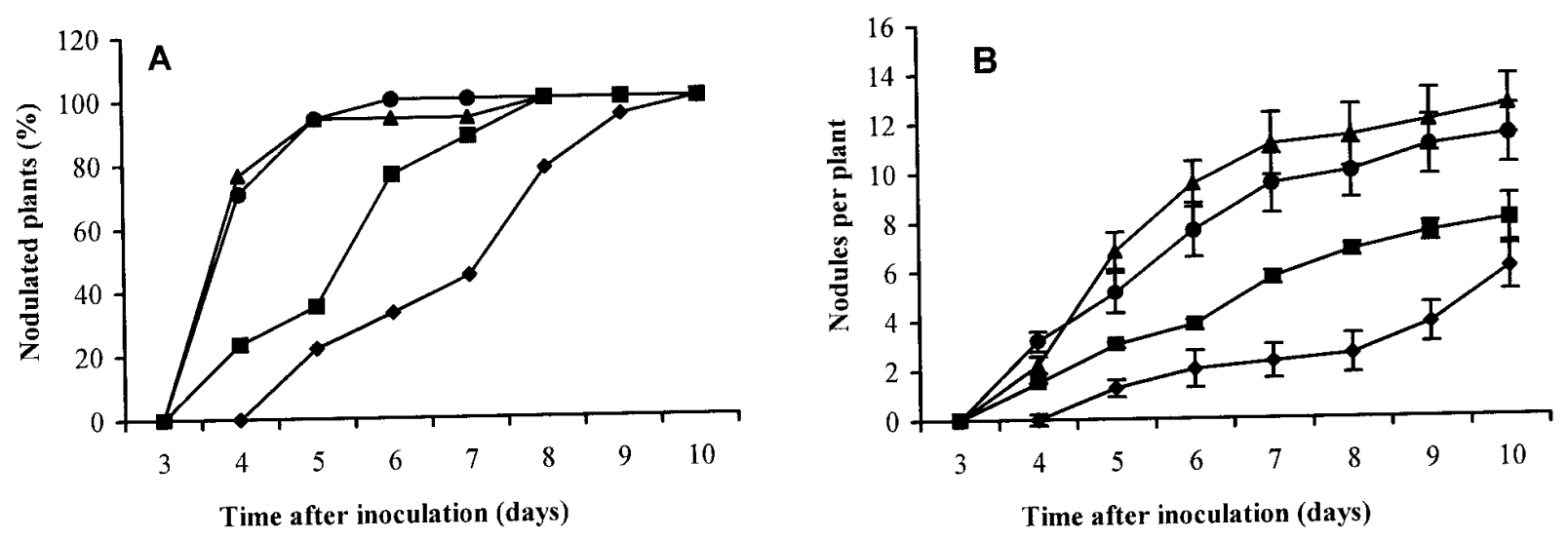

Fig. 2. A, Percentage of nodulated alfalfa plants. B, Number of nodules formed. Roots treated with the following: ( $\mathbf{\square}) 3.75 \mathrm{mM}$ acetic acid; ( $) 7.5 \mathrm{mM}$ acetic acid; (\) $20 \mathrm{mM}$ succinic acid; $(\mathbf{\bullet})$ control; as described in Material and Methods. Experiments were conducted three times with similar results. 
$20 \mathrm{mM}$ succinic acid (impermeable weak acid) adjusted to $\mathrm{pH}$ 5.0 with Tris (extracellular acidification) or by the same acid plus 3.75 or $7.5 \mathrm{mM}$ acetic acid (permeable weak acid) also adjusted to pH 5.0 with Tris. After $30 \mathrm{~min}$, the solutions were thrown out and the roots were washed three times with fresh mineral solution. A third set of tubes was used as the control and treated in the same way as the other two sets except that no acids were added to the mineral medium. The pooled original medium was inoculated with GR4 up to $10^{6}$ cells $\cdot \mathrm{ml}^{-1}$, as above, and distributed equally in all the tubes. Nodule appearance and number of nodules formed were recorded every $24 \mathrm{~h}$.

\section{$\mathrm{H}^{+}$extrusion.}

For the measurement of $\mathrm{H}^{+}$extrusion by roots a Metrohm pH Stat System (Metrohm, Herisau, Switzerland) was used.

Excised alfalfa roots were kept in a cool $0.2 \mathrm{mM} \mathrm{CaSO}_{4}$ solution bubbled with air for $30 \mathrm{~min}$ and, afterwards, incubated in a thermo-regulated $\left(27^{\circ} \mathrm{C}\right)$ Büchner glass. The funnel was mounted on a filter flash and $\mathrm{CO}_{2}$-free air was pumped through the roots, which were placed in a standard assay medium (40 ml per $\mathrm{g}$ fresh weight) containing $50 \mu \mathrm{M} \mathrm{CaSO}_{4}$ and $2 \mathrm{mM} \mathrm{K}_{2} \mathrm{SO}_{4}$. The apparent $\mathrm{H}^{+}$extrusion was estimated over a 4-h period by the amount of $\mathrm{KOH}$ needed in order to maintain the $\mathrm{pH}$ at the selected value $(6.50 \pm 0.02 \mathrm{U})$ according to Davidian et al. (1984). Fusicoccin or calcium ionophore A23187 (Sigma) was added at a final concentration of $125 \mathrm{nM}$ or $5.0 \mu \mathrm{M}$, respectively, to alfalfa roots incubated for $1 \mathrm{~h}$ in the standard assay medium.

\section{ACKNOWLEDGMENTS}

We thank S. R. Long for supplying the plasmid pRmM57. This work has been supported by the Plan Andaluz de Investigación (PAI).

\section{LITERATURE CITED}

Allen, N. S., Bennet, M. N., Cox, D., Shipley, A., Ehrhardt, D. W., and Long, S. R. 1994. Effects of Nod factors on alfalfa root hair $\mathrm{Ca}^{2+}$ and $\mathrm{H}^{+}$currents and cytoskeleton behaviour. Pages 107-114 in: Advances in Molecular Genetics of Plant-Microbe Interaction. M. G. Davis, J. A. Downie, and A. E. Osborne, eds. Kluwer Academic, Dordrecht, The Netherlands.

Baunsgaard, L., Fuglsang, A. T., Jahn, T., Kourthout, H. A. A. J., de Boer, A. H., and Palmgren, M. G. 1998. The 14-3-3 proteins associate with the plant plasma membrane $\mathrm{H}^{+}$-ATPase to generate a fusicoccin binding complex and a fusicoccin-responsive system. Plant J. 2:815-820.

Bertl, A., and Felle, H. 1985. Cytoplasmic pH and root hair cells of Sinapis alba recorded by a $\mathrm{pH}$-sensitive microelectrode. Does fusicoccin stimulate the proton pump by cytoplasmic acidification? J. Exp. Bot. 36:1142-1149.

Brummer, B., Felle, H., and Parish, R. W. 1984. Evidence that acid solution induce plant cell elongation by acidifying the cytosol and stimulating the proton pump. FEBS Lett. 74:223- 227.

Casadesús, J., and Olivares, J. 1979. Rough and fine linkage mapping of the Rhizobium meliloti chromosome. Mol. Gen. Genet. 174:203-209.
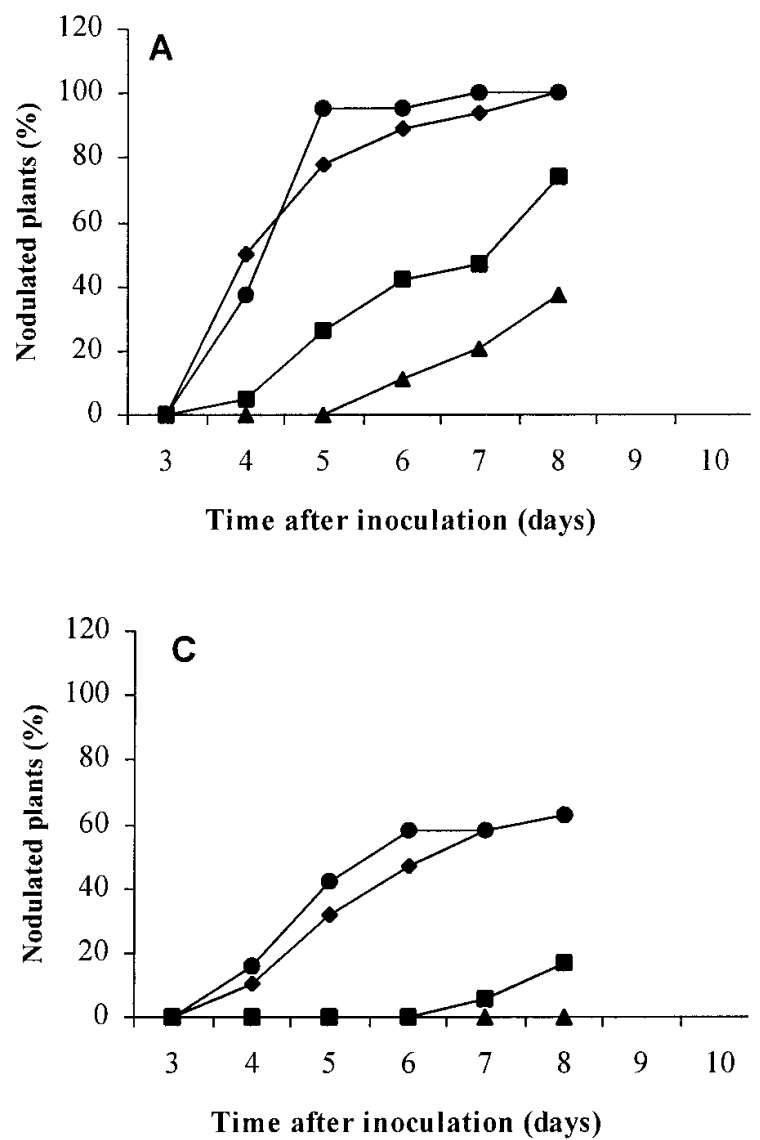
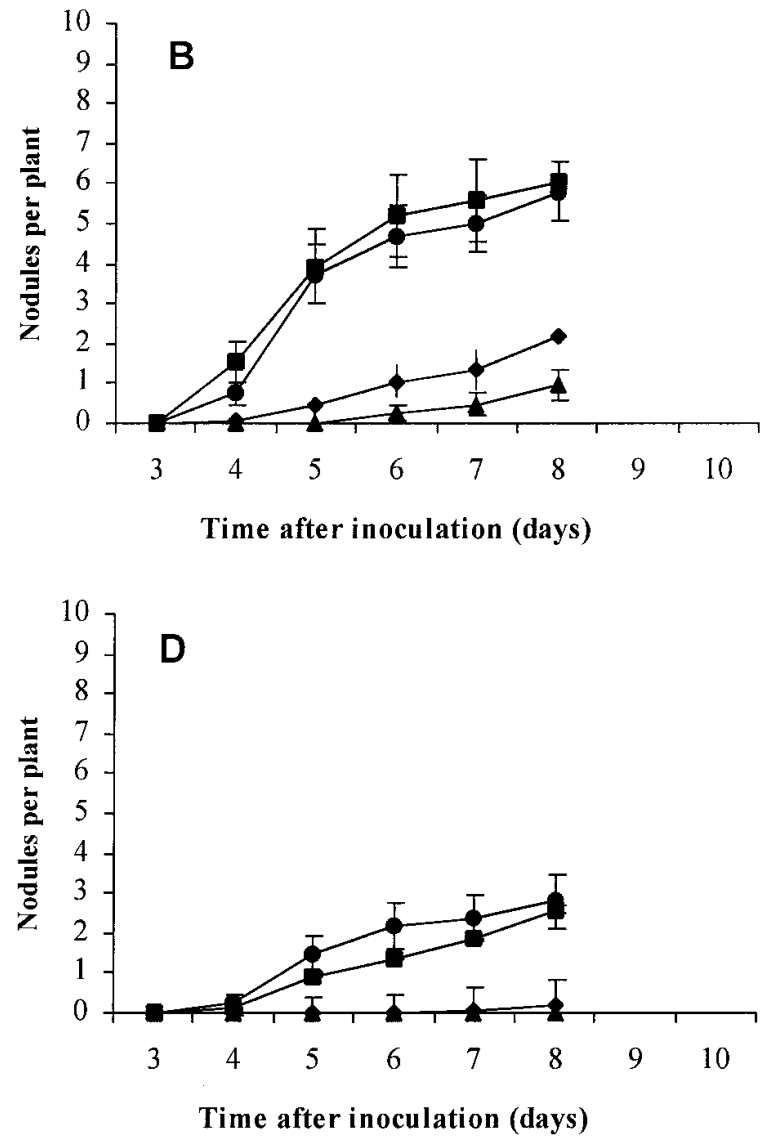

Fig. 3. Nodulation rate of alfalfa roots when calcium is removed from the mineral solution by the addition of EGTA in the (A, B) absence or (C, D) pres-

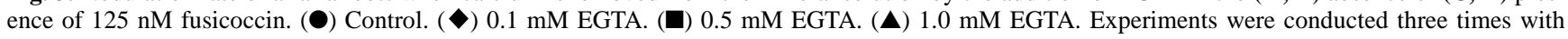
similar results. 
Davidian, J. C., Soler, A., and Grignon, C. 1984. Development of $\mathrm{H}^{+}$ extrusion by barley roots after their scission. Physiol. Vég. 22:163170.

De Michelis, M. I., Rasi-Caldogno, F., Pugliarello, M. C., and Olivari, C. 1996. Fusicoccin binding to its plasma membrane receptor and the activation of the plasma membrane $\mathrm{H}^{+}$-ATPase. Plant Physiol. 110: 957-964.

De Witt, P. J. G. M. 1995. Fungal avirulence genes and plant resistance genes: Unravelling the molecular basis of gene for gene interactions. Adv. Bot. Res. 21:148-177.

Ehrhardt, D. W., Atkinson, B. M., and Long, S. R. 1992. Depolarization of alfalfa root hair membrane potential by Rhizobium meliloti Nod factors. Science 256:998-1000.

Ehrhardt, D. W., Wais, R., and Long, S. R. 1996. Calcium spiking in plant root hairs responding to Rhizobium nodulation signals. Cell 85 : 673-681.

Felle, H. H., Kondorosi, E., Kondorosi, A., and Schultze, M. 1995. Nod signal-induced plasma membrane potential changes in alfalfa root hairs are differentially sensitive to structural modifications of the lipochitooligosaccharide. Plant J. 7:939-947.

Felle, H. H., Kondorosi, E., Kondorosi, A., and Schultze, M. 1996. Rapid alkalinization in alfalfa root hair in response to rhizobial lipochitooligosaccharide signals. Plant J. 10:295-301.

Felle, H. H., Kondorosi, E., Kondorosi, A., and Schultze, M. 1998. The role of ion fluxes in Nod factor signalling in Medicago sativa. Plant $\mathrm{J}$. 13:455-463.

Johansson, F., Sommarin, M., and Larsson, C. 1993. Fusicoccin activates the plasma membrane $\mathrm{H}^{+}$-ATPase by a mechanism involving the C-terminal inhibitory domain. Plant Cell 5:321-327.

Kurkdjian, A. C. 1995. Role of the differentiation of root epidermal cells in Nod factor from Rhizobium meliloti-induced root hair depolarization of Medicago sativa. Plant Physiol. 107:783-790.

Marré, E. 1979. Fusicoccin: A toll in plant physiology. Annu. Rev. Plant Physiol. 30:273-288.
Marré, E., Lado, P., Rasi Caldagno, F., Colombo, R., and De Michelis, M. I. 1974. Evidence for the coupling of proton extrusion to $\mathrm{K}^{+}$uptake in pea internode segments treated with fusicoccin or auxin. Plant Sci. Lett. 3:365-379.

Martínez-Abarca, F., Herrera-Cervera, J. A., Bueno, P., Sanjuan, J., Bisseling, T., and Olivares, J. 1998. Involvement of salicylic acid in the establishment of the Rhizobium meliloti-alfalfa symbiosis. Mol. PlantMicrobe Interact. 11:153-155.

Miller, J. H. 1972. Experiments in Molecular Genetics. Cold Spring Harbor Laboratory, Cold Spring Harbor, NY.

Mulligan, J. T., and Long, S. R. 1985. Induction of Rhizobium melilot nodC expression by plant exudates requires nodD. Proc. Natl. Acad. Sci. USA 82:6609-6613.

Munns, D. 1970. Nodulation of Medicago sativa in solution cultures. V. Calcium and $\mathrm{pH}$ requirements during infection. Plant Soil 32:90-102.

Olivares, J., Casadesús, J., and Bedmar, E. J. 1980. Method for testing degree of infectivity of Rhizobium meliloti strains. Appl. Environ. Microbiol. 56:389-393.

Quigley, N. B., Roberts, D. M., and Ownley, B. H. 1996. Molecular plant-microbe interactions. Trends Plant Sci. 1:366-368.

Roberts, M. R., and Bowles D. J. 1999. Fusicoccin, 14-3-3 proteins, and defense responses in tomato plants. Plant Physiol. 119:1243-1250.

Roldan, M., Belver, A., Rodríguez-Rosales, M. P., and Donaire, J. P. 1992. In vivo and in vitro effect of boron on the plasma membrane proton pump of sunflower roots. Physiol. Plant. 84:49-54.

Schaller, A., and Oecking, C. 1999. Modulation of plasma membrane $\mathrm{H}^{+}$-ATPase activity differentially activates wound and pathogen defense response in tomato plants. Plant Cell 11:263-272.

Serrano, R. 1989. Structure and function of plasma membrane ATPase. Annu. Rev. Plant Physiol. Plant Mol. Biol. 40:61-94.

Vera-Estrella, R., Barckla, B. J., Higgins, V. J., and Blumwald, E. 1994. Plant defense response to fungal pathogens. I. Activation of host plasma membrane $\mathrm{H}^{+}$-ATPase by elicitor-induced enzyme depolarization. Plant Physiol. 104:209-215. 